\title{
A comparison of the sensitivity of immuno- fluorescence and Giemsa for staining Chlamydia trachomatis inclusions in cycloheximide-treated McCoy cells
}

\author{
PE MUNDAY, AP JOHNSON, BJ THOMAS, AND D TAYLOR-ROBINSON \\ From the Medical Research Council Clinical Research Centre, Watford Road, Harrow, \\ Middlesex HAl 3UJ, UK
}

SUMMARY In a clinical study of 190 men with non-gonococcal urethritis, Chlamydia trachomatis inclusions were sought in cycloheximide-treated McCoy cells by an indirect immunofluorescent antibody technique. The method was consistently reliable over a period of two years, and the results were obtained within 24 hours of a patient's attendance. The results correlated with those obtained by Giemsa staining in $91.6 \%$ of patients, and the new method was at least as sensitive as the established Giemsa-staining method.

There have been successive Improvements in techniques for isolating Chlamydia trachomatis, of which the use of cycloheximide-treated McCoy cells ${ }^{1}$ currently provides the most sensitive method. ${ }^{2}$ Thomas et al. ${ }^{3}$ found that it was possible to diagnose a $C$. trachomatis infection within 24 hours of a patient's presentation at a clinic by using cycloheximide-treated cells coupled with immunofluorescence staining of the inclusions. This has enabled us to conduct a clinical study in which the management of patients suffering from nongonococcal urethritis (NGU) was determined by the microbiological findings 24 hours after urethral specimens had been taken. In the course of the study we have taken the opportunity of comparing the sensitivity of immunofluorescence staining with that of the standard Giemsa stain technique for detecting inclusions.

\section{Material and methods}

Men with clinical evidence of NGU were studied over a period of two years, permission having been given by the Ethical Committee. Patients were

Received for publication 28 August 1979 selected on the basis of there being at least 15 polymorphonuclear leucocytes per high-power microscopic field ( $\times 800$ magnification) in the absence of Gram-negative intracellular diplococci in a urethral smear. Only patients who had not taken antibiotics during the previous seven days and who consented to participate in a clinical trial were included. Specimens were obtained by inserting cotton-wool-tipped nasopharyngeal swabs $2-3 \mathrm{~cm}$ into the urethra and expressing them into vials containing $0.8 \mathrm{ml}$ of sucrose-phosphate (2SP) transport medium. All specimens were taken to the laboratory on wet ice and processed within 4 hours of collection.

Each specimen was inoculated on to a pair of untreated McCoy cell monolayers, and the medium was replaced by cycloheximide-containing growth medium (CMGA) 2 hours after centrifugation at $2800 \mathrm{~g}$ for 1 hour at room temperature. ${ }^{3}$

After incubation at $37^{\circ} \mathrm{C}$ for about 16 hours, one of the two monolayers was fixed with methanol and treated with a human serum which had a high antibody titre to lymphogranuloma venereum immunotypes. This was followed by the addition of fluorescein-conjugated anti-human serum as previously described. ${ }^{3}$ Each cell monolayer was examined for fluorescent intracellular inclusions by 177 
an experienced observer. The inclusions were not routinely counted, the qualitative results being used in the clinical trial.

After incubation at $37^{\circ} \mathrm{C}$ for about 48 hours, the second of the duplicate cell monolayers was fixed with methanol and stained by Giemsa. ${ }^{3}$ Each cell monolayer was examined by another observer who had no knowledge of the result of the immunofluorescence (IF) staining. Subsequently, if a discrepancy was found between the results of the two methods, both cell monolayers were reviewed by three experienced observers in order to make a definitive diagnosis.

In addition, 12 pairs of specimens towards the completion of the trial were selected for quantitative examination. In each case, a minimum of 30 microscope fields $(\times 250$ magnification for IF staining) or 90 fields ( $\times 400$ magnification for Giemsa staining) was examined and the total number of inclusions present in each monolayer of cells was calculated.

\section{Results}

One hundred and ninety specimens were examined. Sixty-seven of these produced inclusions in cell monolayers which were detected by both IF and Giemsa staining or by one or other method, an overall isolation rate for C. trachomatis of $35 \%$.

The results obtained by the two methods for 174 $(91.6 \%)$ of the specimens were the same (58 chlamydia-positive, 105 chlamydia-negative, and 11 tests invalid because of disrupted cell monolayers). Thus there was a discrepancy between the two methods for only $16(8.4 \%)$ of the specimens.

Table Comparison of cycloheximide-treated cells examined by immunofluorescence at 19 hours with cells stained by Giemsa at 48 hours for isolation of C. trachomatis from urethral specimens

\begin{tabular}{llrl}
\hline Specimen & \multicolumn{2}{l}{$\begin{array}{l}\text { No. of inclusions/coverslip } \\
\text { in cells stained by }\end{array}$} & $\begin{array}{l}\text { No. of inclusions } \\
\text { (ratio of IF to Giemsa) }\end{array}$ \\
\cline { 2 - 3 } & IF at $19 h$ & Giemsa at $48 h$ & \\
\hline 41 & 3230 & 1985 & $1 \cdot 6: 1$ \\
82 & 1765 & 1200 & $1 \cdot 5: 1$ \\
181 & 1038 & 81 & $12 \cdot 8: 1$ \\
182 & 7719 & 1462 & $5 \cdot 2: 1$ \\
187 & 417 & 144 & $2 \cdot 9: 1$ \\
192 & 4329 & 2806 & $1 \cdot 5: 1$ \\
194 & 1730 & 451 & $3 \cdot 8: 1$ \\
196 & 4150 & 2977 & $1 \cdot 4: 1$ \\
363 & 20 & 9 & $2 \cdot 2: 1$ \\
376 & 29 & 18 & $1 \cdot 6: 1$ \\
377 & 291 & 126 & $2 \cdot 3: 1$ \\
393 & 94 & 9 & $10 \cdot 4: 1$ \\
Median & & & $2 \cdot 25: 1$ \\
\hline
\end{tabular}

Further examination by three observers resolved this discrepancy for 12 of these ( 5 chlamydiapositive, 7 chlamydia-negative). In four cases only $(2 \cdot 1 \%)$ was the final diagnosis different by the two methods. In three of these the IF-stained cell monolayers were positive and the Giemsa-stained monolayers were negative, and in one case only was the IF-stained monolayer negative and the Giemsastained monolayer positive.

Twelve specimens were examined quantitatively In every case, more inclusions were seen after IF staining at 19 hours than after Giemsa staining at 48 hours (Table). The ratio of the number of inclusions detected by IF to that detected by Giemsa was not the same for each specimen, but on average at least twice as many inclusions were seen after IF staining than after Giemsa staining.

\section{Discussion}

In this study we used McCoy cells treated with cycloheximide 3 hours after inoculation of the specimens, since we have found that this renders them more sensitive than other procedures. ${ }^{2}$ Our previous observations ${ }^{3}$ showed that IF staining of inclusions provided a rapid technique for the detection of chlamydiae, and that it was probably at least as sensitive as Giemsa staining of inclusions, although only a few clinical specimens were examined.

We felt, therefore, that it was important to study the IF-staining technique in a clinical situation to determine its validity as an alternative to the established and simpler Giemsa technique, and we took the opportunity to do so in a study of men suffering from NGU. The isolation rate, based on the results obtained by both staining techniques, was $35 \%$. We regard this as acceptable in an unselected population which included about $20 \%$ of patients with chronic and antibiotic-resistant NGU. Since there was more than $90 \%$ agreement between IF staining and Giemsa staining, the IF technique is sufficiently reliable in practice to enable a diagnosis $\frac{7}{0}$ of chlamydial infection to be made within 24 hours of a specimen being taken from a male patient. In $N$ addition, on the basis of a quantitative estimation of $N$ inclusions, the technique appears to be even more ${ }_{N}$ sensitive than Giemsa staining. However, we have $\omega$ not found that IF staining significantly increased the isolation of $C$. trachomatis and we do not suggest $\stackrel{Q}{C}$ that it should be used with this outcome in mind, $\overparen{D}$ although it might occur if very large numbers of samples containing few organisms were to be tested. The value of the technique is the ability to reach a diagnosis of chlamydial infection at least 24 hours earlier than is possible using conventional techniques. 


\section{References}

${ }^{1}$ Ripa K T, Mårdh P A. Cultivation of Chlamydia trachomatis in cycloheximide-treated McCoy cells. J Clin Microbiol 1977; 6: 328-331.

${ }^{2}$ Evans R T, Taylor-Robinson D. Comparison of various McCoy cell treatment procedures used for the detection of Chlamydia trachomatis. J Clin Microbiol 1979; 10: 198-201.
${ }^{3}$ Thomas B J, Evans R T, Hutchinson G R, TaylorRobinson D. Early detection of chlamydial inclusions combining the use of cycloheximide-treated McCoy cells and immunofluorescence staining. J Clin Microbiol 1977; 6: 285-292.

Requests for reprints to: Dr PE Munday, Medical Research Council Clinical Research Centre, Watford Road, Harrow, Middlesex HA1 3UJ, UK.

\section{The January 1980 issue}

\section{THE JANUARY 1980 ISSUE CONTAINS THE FOLLOWING PAPERS}

Recommendation for reference method for determination by centrifugation of packed cell volume of blood INTERNATIONAL COMMITTEE FOR STANDARDIZATION IN HAEMATOLOGY EXPERT PANEL ON BLOOD CELL SIZING

Sex-related differences in the haematological effects of excessive alcohol consumption DM CHALMERS, I CHANARIN, S MACDERMOTT, AND AJ LEVI

Long-term storage of blood in liquid nitrogen, and the response of the recovered red cells to haemagglutination by viruses FG RODGERS

Adult pulmonary cytomegalic inclusion disease: report of a case JD BROWNING, IAR MORE, AND JF BOYD

Improved economics of $\mathrm{HBsAg}$ screening with commercial radioimmunoassay reagents R HOPKINS, SYLVIA ROSS, T JORDAN, AND AD WATT

Susceptibility to rubella in a pregnant population after the introduction of vaccination E BROADBENT, N AJINA, AND ROSALINDE HURLEY

Serological studies on 40 cases of mumps virus infection $R$ FREEMAN AND MH HAMBLING

Counter immunoelectrophoresis as a rapid screening test for amoebic liver abscess JENNIFER HC TOSSWILL, DS RIDLEY, AND DC WARHURST

Automated methods for identification of bacteria from clinical specimens SHOSHANA BASCOMB AND RC SPENCER

A shortened scheme for the identification of indifferent streptococci SHEENA A WAITKINS, LYN C BALL, AND CHERRY AM FRASER
Use of the API-ZYM system in rapid identification of $a$ and non-haemolytic streptococci SHEENA A WAITKINS, LYN C BALL, AND CHERRY AM FRASER

Significance of bacterial and white cell counts in midstream urines PJ LITTLE, BARBARA A PEDDIE, AND ADRIENNE R SINCOCK

Multiple selective media for the isolation of anaerobic bacteria from clinical specimens MWD WREN

Bacteriological examination of pus from abscesses of the central nervous system JOHN DE LOUVOIS

An assessment of the Mi-Mark endometrial sampling technique JULIE CROW, H GORDON, AND ELIZABETH HUDSON

Haemangioleiomyomatous tumour of the lung AJAIB SOORAE AND HOSHANG BHARUCHA

Ionised calcium in pathological human bile D JUNE SUTOR, LYNETTE I WILKIE, AND MJ JACKSON

Applications of a modified Cortipac procedure for the estimation of urinary free cortisol in various clinical situations PETER WEST

\section{Technical methods}

Quality control in agar-dilution sensitivity-testing by direct assay of the antibiotic in the solid medium J CLARE FRANKLIN

Demarcation of antigen preparations on object slides in the immunofluorescent antibody test S RÄISÄNEN, I RANTALA, AND H HELIN

Simple microphotometry KP WEST AND F WALKER

Letter to the Editor

Book reviews

Copies are still available and may be obtained from the PUBLISHING MANAGER, BRITISH MEDICAL ASSOCIATION, TAVISTOCK SQUARE, LONDON WC1H 9JR, price $£ 3 \cdot 00$, including postage 